\title{
Pengaruh Penggunaan Aplikasi "SI Pesek" (Stop Tindakan Pelecehan Seksual) Terhadap Pengetahuan Tentang Personal Safety Skill pada Anak Usia Prasekolah di TK Manba'Ul Huda Bekasi Jawa Barat
}

\author{
*Edo Septa Beri'), Titin Sutini' ${ }^{2)}$, Rohadi Haryanto ${ }^{3)}$
}

Program Studi Magister Keperawatan Fakultas Ilmu Kedokteran Universitas Muhammadiyah Jakarta

Corresponden author: allyssacc.berry@gmail.com

Received : 4 Desember $2020 \quad$ Accepted : 23 September $2021 \quad$ Published: 30 September 2021

DOI: https://doi.org/10.37012/jik.v13i2.407

\begin{abstract}
ABSTRAK
Pelecehan seksual anak adalah melibatkan, membujuk atau memaksa seseorang anak ambil bagian dalam kegiatan seksual, atau mendorong anak berperilaku dalam kontak seksual yang tidak pantas dan ini merupakan fenomena yang sering terjadi. Tujuan penelitian ini adalah mengidentifikasi pengaruh penggunaan aplikasi "SI Pesek" terhadap pengetahuan personal safety skill pada anak usia pra sekolah di TK Manba'ul Huda Bekasi Jawa Barat. Desain penelitian menggunakan quasi eksperimen non equivalent control group design dengan jumlah responden sebanyak 30 orang dan dibagi menjadi kelompok intervensi dan kelompok kontrol. Hasil penelitian didapatkan ada pengaruh pemberian aplikasi "si pesek" terhadap pengetahuan personal safety skill dengan nilai $p$ value $0.000(<0.05)$. Ada pengaruh factor confounding pemberian "si pesek" terhadap perubahan pengetahuan anak, yaitu usia dengan $p$ value $0.04(<0.05)$, lingkungan dengan $\mathrm{p}$ value $0.04(<0.05)$, sosial budaya dengan $\mathrm{p}$ value $0.04(<0.05)$, serta informasi yang paling signifikan dengan $\mathrm{p}$ value $0.02(<0.05)$. Berdasarkan hasil penelitian bahwa aplikasi "si pesek" dapat direkomendasikan sebagai salah satu edukasi dalam pelayanan keperawatan anak guna mencegah kekeresan seksual pada anak usia prasekolah
\end{abstract}

Kata Kunci: Anak Prasekolah, Pendidikan Seksual, Kekerasan Seksual.

\begin{abstract}
Sexual child abuse is involving, persuading, or forcing a child to take part in sexual activities or encouraging the child to behave inappropriate sexual contact, and this is a frequent phenomenon. The purpose of this study was to identify the effect of using the application "SI Pesek" on personal safety skill knowledge in preschool children at Manba'ul Huda, Bekasi, West Java. The research design used was the equations experimental non equivalent control grop design with 30 respondents divided into two groups, intervention dan control. The result showed that the ads were the effect of giving the application "si pesek" on personal knowledge of safety skill with a p value $0.000(<0.05)$. There is an effect of confounding factors on children knowledge, namely age with $p$ value $0.04(<0.05)$, environment with $p$ value $0.04(<0.05)$, socio cultural with $p$ value $0.04(<0.05)$ and information is the most significant with $p$ value $0.02(<0.05)$. Based on the research results the application "si pesek" can be recommended as an educational tool in child nursing services to prevent sexual violence in preschoolers.
\end{abstract}

Keywords: Preschool Children, Sexual Education, Sexual Abuse. 


\section{PENDAHULUAN}

Pada usia ini anak memiliki karakteristik tertentu yang khas dan tidak sama dengan orang dewasa. Mereka selalu aktif, dinamis, antusias dan ingin tahu terhadap apa yang dilihat, didengar, dirasakan, dan seolah-olah tidak pernah berhenti berekplorasi dan belajar. Anak bersifat egosentris, memiliki rasa ingin tahu secara alamiah. Anak merupakan mahluk sosial, unik dan kaya fantasi, memiliki daya perhatian yang pendek, dan merupakan masa yang paling potensial untuk belajar (Dewi, 2013).

Menurut data dari American Academy of Child and Adolescent Psychiatry pada bulan November 2014, dikatakan bahwa kekerasan seksual terhadap anak terjadi sampai 80.000 kali dalam setahun. Jumlah ini belum termasuk jumlah yang tidak terdata, baik karena para korban terlalu takut untuk melaporkan atau karena proses pembuatan laporan yang dipersulit. National Children's Alliance (NCA) pada tahun 2013 juga melaporkan terdapat 202.265 kasus, tahun 2014 jumlah kasus kekerasan seksual pada anak meningkat menjadi 205.438 kasus. Angka kejadian pelecehan seksual pada anak di Indonesia yang didapat dari Pusat data dan informasi Komisi Perlindungan Anak Indonesia (Pusdatin KPAI) tahun 2018, sejauh ini telah mencatat setidaknya terdapat 965 kasus pelanggaran hak anak sepanjang Januari hingga Juni. Dari 965 kasus tersebut $52 \%$ didominasi oleh kejahatan seksual pada anak.

Menurut data KPAI dari tahun 2010 hingga tahun 2014 tercatat sebanyak 21.869.797 kasus pelanggaran hak anak, yang tersebar di 34 provinsi, dan 179 kabupaten dan kota. Sebesar $42-$ $58 \%$ dari pelanggaran hak anak tersebut merupakan kejahatan seksual pada anak, dan 80,23\% pelaku kekerasan seksual pada anak adalah orang terdekat, 19,77\% adalah orang tidak dikenal. KPAI (2019) menjelaskan data korban kejahatan seksual pada anak setiap tahunnya mengalami peningkatan. Pada tahun 2010 terdapat 859 kasus, tahun 2011 terdapat 1.407 kasus, tahun 2012 terdapat 1.634 kasus, dan tahun 2013 terdapat 2.070 kasus. Sedangkan pada tahun 2014 hingga tahun 2019 angka kejadian mengalami fluktuatif, tahun 2014 terdapat 600 kasus, tahun 2015 terdapat 1.709 kasus, tahun 2017 terdapat 1.581 kasus, tahun 2018 terdapat 501 kasus dan pada periode Januari hingga Mei 2019 terdapat 236 kasus pelecahan seksual pada anak.

Kepala dinas pemberdayaan perlindungan perempuan dan anak (DPPPA, 2018) Kota Bekasi, mengatakan bahwa jumlah kekerasan seksual anak di Bekasi pada tahun 2015 mencapai 59 kasus, kemudian tahun 2016 naik menjadi 77 kasus, dan di tahun 2017 menjadi 104 kasus, selanjutnya tahun 2018 tercatat 5 kasus dan tahun 2019 per 11 Desember terdapat 23 kasus pelecehan seksual pada anak. Berdasarkan studi pendahuluan yang dilakukan kepada anak dan orangtua di TK Manba'ul Huda Bekasi Jawa Barat dengan melakukan wawancara, didapatkan 
data bahwa anak tidak tahu apa itu pelecahan seksual, bagaimana anak harus berperilaku atau berbuat ketika ada orang yang meraba bagian tubuhnya dan bagaimana anak harus melakukan pencegahannya disaat dalam kondisi tersebut. Kemudian orangtua juga tidak mengetahui terkait dengan bagaimana memberikan pemahaman tentang pengetahuan dan pencegahan pelecehan seksual kepada anak, karena orangtua menganggap hal ini merupakan sesuatu yang tabu. Orangtua juga tidak faham bagaimana cara memberikan pembelajaran kepada anak - anaknya. Kepala Sekolah dan Guru merasa khawatir dengan maraknya kejadian pelecehan seksual yang terjadi pada anak usia prasekolah, hal ini semakin memperbesar rasa kehawatiran atas kejadian pelecehan seksual yang menimpa seorang anak berusia 6 tahun di Pondok Ungu Permai Bekasi Jawa Barat, dimana pelakunya adalah seorang penjual susu keliling (DPPPA, 2019).

\section{METODE}

Penelitian ini adalah quasi eksperimen dengan desain non equivalent menggunakan satu kelompok eksperimen dengan kelompok pembanding, dengan diawali sebuah test awal (pre test) yang diberikan kepada dua kelompok, kemudian diberikan perlakuan (treatment), dan diakhiri dengan sebuah tes akhir (post test) yang diberikan kepada kedua kelompok (Sugiyono, 2017). Populasi dalam peneltian ini adalah siswa dan siswi usia prasekolah (usia 5-6 tahun) yang ada di TK Manba’ul Huda Bekasi Jawa Barat sebanyak 50 orang. Penelitian ini terdiri dari 2 kelompok yaitu kelompok intervensi dan kontrol, masing-masing setiap kelompok terdiri dari 15 responden sehingga total sampel yang dilibatkan dalam penelitian ini adalah 30 responden. Tempat penelitian ini akandilakukan di TK. Manba'ul Huda Bekasi Jawa Barat karena TK tersebut belum pernah dilakukan pendidikan kesehatan khususnya tentang pelecehan seksual.

\section{HASIL DAN PEMBAHASAN}


Tabel 1.

Distribusi Frekuensi Berdasarkan Usia Anak, Informasi, Lingkungan, dan Sosial Budaya pada Kelompok Intervensi dan Kelompok Kontrol di TK Manba’ul `Huda Bekasi Jawa Barat Mei-Juni 2020

\begin{tabular}{lcccc}
\hline \multirow{2}{*}{ Variabel } & \multicolumn{2}{c}{ Kelompol Intervensi } & \multicolumn{2}{c}{ Kelompok Kontrol } \\
\cline { 2 - 5 } & Jumlah & $\mathbf{\%}$ & Jumlah & $\mathbf{\%}$ \\
\hline Usia & & & & \\
5 tahun & 4 & 26.7 & 6 & 40.0 \\
6 tahun & 11 & 73.3 & 9 & 60.0 \\
Total & $\mathbf{1 5}$ & $\mathbf{1 0 0}$ & $\mathbf{1 5}$ & $\mathbf{1 0 0}$ \\
\hline Informasi & & & & \\
Ada & 9 & 60.0 & 3 & 20.0 \\
Tidak ada & 6 & 40.0 & 12 & 80.0 \\
Total & $\mathbf{1 5}$ & $\mathbf{1 0 0}$ & $\mathbf{1 5}$ & $\mathbf{1 0 0}$ \\
\hline Lingkungan & & & & \\
Baik & 9 & 60.0 & 3 & 20.0 \\
Buruk & 6 & 40.0 & 12 & 80.0 \\
Total & $\mathbf{1 5}$ & $\mathbf{1 0 0}$ & $\mathbf{1 5}$ & $\mathbf{1 0 0}$ \\
\hline Sosial Budaya & & & & \\
Mendukung & 10 & 66.7 & 2 & 13.3 \\
Tidak mendukung & 5 & 33.3 & 13 & 86.7 \\
Total & $\mathbf{1 5}$ & $\mathbf{1 0 0}$ & $\mathbf{1 5}$ & $\mathbf{1 0 0}$ \\
\hline
\end{tabular}

Tabel 2.

Distribusi Frekuensi Pengetahuan Anak Menurut Kelompok Intervensi dan Kelompok Kontrol Sebelum dan Sesudah Intervensi "Si Pesek" di TK Manba'ul Huda Bekasi Jawa Barat, Mei-Juni 2020

\begin{tabular}{lcc}
\hline Kelompok Intervensi & Jumlah & \% \\
\hline Sebelum & 7 & 46.7 \\
Rendah & 8 & 53.3 \\
Sedang & 0 & 0 \\
Baik & $\mathbf{1 5}$ & $\mathbf{1 0 0}$ \\
Total & & \\
Sesudah & & \\
Rendah & 0 & 0 \\
Sedang & 5 & 33.3 \\
Baik & 10 & 66.7 \\
Total & $\mathbf{1 5}$ & $\mathbf{1 0 0}$ \\
\hline Kelompok Kontrol & & \\
Sebelum & & \\
Rendah & 12 & 80.0 \\
Sedang & 3 & 20.0 \\
Baik & 0 & 0 \\
Total & $\mathbf{1 5}$ & $\mathbf{1 0 0}$ \\
\hline Sesudah & & \\
Rendah & 4 & 26.7 \\
Sedang & 11 & 73.3 \\
Baik & 0 & 0 \\
Total & $\mathbf{1 5}$ & $\mathbf{1 0 0}$ \\
\hline
\end{tabular}

\section{Analisis bivariat}

Tabel 3.

Perbedaan pengetahuan tentang personal safety skill pada kelompok intervensi dan 
kelompok kontrol sebelum dan sesudah diberikan "si pesek" di TK Manba'ul Huda Bekasi Jawa Barat, Mei-Juni 2020

\begin{tabular}{lccc}
\hline \multicolumn{1}{c}{ Variabel } & Mean & SD & Pvalue \\
\hline Kelompok Intervensi & & & \\
\hline Pengetahuan anak & & & \\
Sebelum & 9.00 & 1,309 & 0,000 \\
Sesudah & 17.80 & 1.320 & \\
Selisih $(\Delta)$ & 8.80 & & \\
\hline Kelompok Kontrol & & & \\
\hline Pengetahuan anak & & & \\
Sebelum & 6.93 & 0.704 & 0,183 \\
Sesudah & 8.40 & 0.910 & \\
Selisih $(\Delta)$ & 1.46 & & \\
\hline
\end{tabular}

Tabel 4.

Perbedaan pengetahuan tentang personal safety skill antara kelompok intervensi dan kelompok kontrol di TK Manba'ul Huda Bekasi Jawa Barat

\begin{tabular}{llccl}
\hline Variabel & Kelompok & Mean & SD & Sig (2. tailed ) \\
\hline Pengetahuan & Intervensi & 13.40 & 6.658 & 0.000 \\
Pengetahuan & Kontrol & 7.67 & 1.093 & \\
\hline
\end{tabular}

\section{Analisa Multivariat}

Tabel 5.

Hasil Analisis Bivariat Masing-Masing Variable Confounding

\begin{tabular}{|c|c|c|}
\hline Variabel & $p$ value & Keterangan \\
\hline Umur & 0.023 & Kandidat \\
\hline Lingkungan & 0.023 & Kandidat \\
\hline Informasi & 0.006 & Kandidat \\
\hline Sosial Budaya & 0.023 & Kandidat \\
\hline
\end{tabular}

Pemodelan awal multivariate

Tabel 6. 
Hasil Uji Regresi Logistik pengaruh factor confounding terhadap nilai mean pengetahuan tentang personal safety skill anak usia prasekolah di TK Manba'ul Huda

Bekasi Jawa Barat, Mei-Juni 2020

\begin{tabular}{|c|c|c|c|c|c|c|c|}
\hline \multirow{2}{*}{$\begin{array}{c}\text { Confounding } \\
\text { (*Pengetahua } \\
\text { n) }\end{array}$} & \multirow[t]{2}{*}{ B } & \multirow[t]{2}{*}{ S.E. } & \multirow[t]{2}{*}{ Wald } & \multirow[t]{2}{*}{ Sig. } & \multirow[t]{2}{*}{$\operatorname{Exp}(B)$} & \multicolumn{2}{|c|}{$\begin{array}{c}\text { 95\% C.I.for } \\
\operatorname{EXP(B)}\end{array}$} \\
\hline & & & & & & Lower & Upper \\
\hline Umur & 2.773 & 1.369 & 4.100 & 0.043 & 16.000 & 1.093 & 234.248 \\
\hline Lingkungan & 2,773 & 1,369 & 4,100 & 0,043 & 16.000 & 1,093 & 234.248 \\
\hline Informasi & 3.584 & 1.537 & 5.439 & 0,020 & 36.000 & 1.772 & 731.562 \\
\hline $\begin{array}{l}\text { Sosial } \\
\text { Budaya }\end{array}$ & 2.773 & 1.369 & 4.100 & 0.043 & 16.000 & 1.093 & 234.248 \\
\hline
\end{tabular}

Pemodelan akhir

Tabel 7.

Hasil akhir pengaruh variable confounding terhadap pengetahuan tentang personal safety skill anak usia prasekolah di TK Manba'ul Huda Bekasi Jawa Barat, Mei-Juni 2020

\begin{tabular}{|c|c|c|c|c|c|c|c|}
\hline \multirow{2}{*}{$\begin{array}{c}\text { Confounding } \\
\text { (*Pengetahuan } \\
\text { ) }\end{array}$} & \multirow{2}{*}{ B } & \multirow{2}{*}{ S.E. } & \multirow{2}{*}{ Wald } & \multirow{2}{*}{ Sig. } & \multirow{2}{*}{$\begin{array}{c}\operatorname{Exp}(B \\
)\end{array}$} & \multicolumn{2}{|c|}{ 95\% C.I.for EXP(B) } \\
\hline & & & & & & Lower & Upper \\
\hline Informasi & 3.584 & 1.537 & 5.439 & 0.020 & 36.000 & 1.772 & 731.562 \\
\hline Lingkungan & 2,773 & 1,369 & 4,100 & 0,043 & 16.000 & 1,093 & 234.248 \\
\hline Umur & 2.773 & 1.369 & 4.100 & 0,043 & 16.000 & 1.093 & 234.248 \\
\hline $\begin{array}{l}\text { Sosial } \\
\text { Budaya }\end{array}$ & 2.773 & 1.369 & 4.100 & 0.043 & 16.000 & 1.093 & 234.248 \\
\hline
\end{tabular}

\section{Pembahasan}

Pada anak kelompok intervensi didapatkan rata - rata nilai mean pengetahuan tentang personal safety skill sebelum diberikan intervensi "si pesek" dengan rata - rata nilai mean adalah 8.80 dan rata - rata nilai mean pengetahuan setelah diberikan intervensi "si pesek" adalah 17.80. Artinya pengetahuan anak setelah diberikan intervensi meningkat secara signfikan dari sebelumnya. Hal ini didukung oleh penelitian yang dilakukan oleh Natalia Devi Oktarina (2019), yang berjudul pengaruh media cerita bergambar pada anak usia prasekolah dengan menggunakan media cerita bergambar yakni didapatkan nilai pengetahuan setelah diberikan intervensi dengan nilai post test sebesar 6.99 dibandingkan dengan sebelum diberikan intervensi dengan nilai pre test sebesar 4.82 dengan nilai $(p<0.05)$.

Pengaruh variable confounding terhadap pengetahuan personal safety skill anak usia prasekolah. Hasil penelitian menunjukkan bahwa factor confounding untuk usia, informasi, lingkungan dan social budaya mempunyai pengaruh terhadap pengetahuan personal safety skill 
anak usia prasekolah sedangkan. Nilai $p$ value pada pengaruh usia anak terhadap pengetahuan personal safety skill yaitu $0,04(<0,05)$, nilai $p$ value pada pengaruh lingkungan terhadap pengetahuan personal safety skill yaitu $0,04(<0,05)$, nilai pengaruh sosial budaya terhadap pengetahuan personal safety skill yaitu $0,04(<0,05)$ dan nilai $p$ value pada pengaruh informasi terhadap pengetahuan personal safety skill 0,02 $(<0,05)$

Jadi dapat disimpulkan berdasarkan keempat variable confounding diatas yang mempunyai nilai yang sangat signifikan dan mempengaruhi pengetahuan tentang personal safety skill adalah informasi dengan nilai $p$ value yaitu $0.02(p<0.05)$. Hasil penelitian yang dilakukan oleh Istiqomah Aprilaz (2016) dengan judul perbandingan efektifitas metode video dan cerita boneka dalam pendidikan seksual terhadap pengetahuan anak prasekolah didapatkan nilai $p$ value $(p<0.05)$ yang artinya ada pengaruh signifikan pendidikan seksual dengan metode video maupun cerita boneka terhadap pengetahuan anak.

Berdasarkan keempat variable confounding yang mempunyai nilai yang sangat signifikan dan mempengaruhi pengetahuan tentang personal safety skilladalah informasi dengan nilai $p$ valueyaitu $0.02(p<0.05)$.Jadi dapat disimpulkan bahwa semakin diberikannya informasi kepada anak, maka tingkat pengetahuan anak tentang personal safety skill menjadi meningkat jika diberikan aplikasi "si pesek".

\section{Aplikasi Konsep Health Promotian Model Nola J Pender terhadap pengetahuan anak tentang personal safety skill anak prasekolah}

Hasil penelitian menunjukan bahwa ada perbedaan pengetahuan anak usia prasekolah sebelum dan sesudah intervensi "si pesek" pada kelompok intervensi. Dan tidak ada perbedaan pengetahuan anak usia prasekolah sebelum dan sesudah pada kelompok kontrol tanpa diberikan "si pesek". Hasil ini juga menunjukan bahwa terdapatnya perbedaan yang signifikan rata-rata pengetahuan tentang personal safety skill antara kelompok intervensi dan kelompok kontrol.

Peneliti berasumsi menurut hasil penelitian, teori dan penelitian sebelumnya, bahwa pada umumnya pengetahuan dapat diperoleh dari informasi yang disampaikan. Informasi tentang objek atau yang berkaitan dengan pengetahuan diperoleh dari semakin tinggi tingkat pengetahuan seseorang, maka akan semakin mudah untuk menerimanya.

\section{SIMPULAN DAN REKOMENDASI}

Sebagian besar responden dalam penelitian ini adalah anak usia prasekolah berusia 6 tahun, sebagian besar belum mendapatkan informasi, lingkungan yang buruk, dengan sosial budaya yang tidak mendukung. Terdapat perbedaan pengetahuan tentang personal safety skill pada 
anak usia prasekolah di TK Manba’ul Huda Bekasi Jawa Barat sebelum dan sesudah diberikan intervensi "si pesek" pada kelompok intervensi. Tidak terdapat perbedaan pengetahuan tentang personal safety skill pada anak usia prasekolah di TK Manba'ul Huda Bekasi Jawa Barat sebelum dan sesudah intervensi "si pesek" pada kelompok kontrol.

Bagi tenaga kesehatan Peneliti menyarankan kepada tenaga kesehatan untuk senantiasa lebih aktif dalam memberikan program kesehatan pendidikan seksual dan mengedukasi dalam mengatasi masalah kekerasan seksual pada anak. Edukasi yang diberikan kepada anak juga harus disertai dengan pendampingan dan penguatan oleh tenaga kesehatan agar menghasilkan perilaku yang baik dalam pencegahan kekerasan seksual. Edukasi ini perlu diberikan kepada anak yang masih memiliki keterbatasan informasi, umur yang lebih muda, lingkungan dan social budaya yang tidak kondusif.

\section{REFERENSI}

1. Arif S. Sadiman, dkk (2011), Manfaat dari media pembelajaran. Jurnal Metodik Didaktik Universitas Pendidikan Indonesia Kampus Serang.

2. Arsyad, Azhar. (2011). Media pembelajaran: cetakanke - 15. Jakarta :Rajawali

3. Pers.

4. Dewi, (2013). Teori \& konsep tumbuh kembang anak usia prasekolah. Yogjakarta : Huha Medika.

5. Dewi, O. R. K. (2013). Study komparatiif perkembangan anak usia pra sekolah yang mengikuti program playgroup dan yang tidak mengikuti program playgroup di Desa Tapelan, Kecamatan Balerejo, Madiun : Universitas Muhammadiyah Ponorogo. Retrieved from http://eprints.umpo.ac.id/2162/1/jkptumpo-gdl-okyrositak-475-1abstrak\%2C-a.pdf. Diunduh tanggal 22 Sep 2020

6. Data American Academy of Child and Adolescent Psychiatry, 2014

7. Data National Children's Alliance (NCA) pada tahun 2013

8. Data Komisi Perlindungan Anak Indonesia (KPAI), 2019. Angka Kejadian Kasus Kekerasan Seksual Pada Anak

9. Data Kepala dinas pemberdayaan perlindungan perempuan dan anak (DPPPA, 2018) jumlah kekerasan seksual anak di Bekasi pada tahun 2015 
10. Komisi Perlindungan Anak Indonesia, (2014). Perilaku kekerasan seksual pada anak usia prasekolah tiap tahun meningkat. http//www.kpai.go.id/berita/kpai-perilakukekerasan-terhadap-anak, 14 juni 2014.

11. Supartini, Y. (2004). Buku ajar konsep dasar keperawatan anak. Penerbit buku kedokteran. Jakarta: EGC.

12. Sugiyono. (2017). Metode Penelitian Kuantitatif, Kualitatif, R \& D. Bandung: CV Alfabeta. 